\title{
"Contra a prudência e a providência": os Padres Jacob e João de Barros e a colonização no sertão das jacobinas
}

\author{
"Against prudence and providence": Parents \\ Jacob and João de Barros and colonization in the "backwoods" of jacobinas
}

Ane Mecenas ${ }^{*}$

Resumo: Na segunda metade do século XVII, após a Restauração Portuguesa, intensificou-se o povoamento do sertão da América portuguesa. O processo, definido na documentação como "expansão para os caminhos de dentro", visava à constituição de aldeamentos e à formação de alianças, com o intuito de garantir segurança no acesso comercial às rotas dos criadores de gado que seguiam da Bahia ao Piauí, bem como a constituição de um grupo de índios que coibisse a formação de quilombos nas impenetráveis rotas do sertão. Mais uma vez, as ordens religiosas foram incumbidas da tarefa de organizar as aldeias, disciplinar as almas e fornecer mão de obra nas entradas para o sertão. O contexto de criação dos aldeamentos é apresentado com base na documentação do Arquivo Ultramarino e da que se encontra na coleção Documentos Históricos da Biblioteca Nacional do Rio de Janeiro. Esse trabalho tem como objetivo os múltiplos atores envolvidos no povoamento do sertão da Bahia, com destaque para os jesuítas, que se tornaram os mediadores entre os mundos dos índios e os interesses dos curraleiros, responsáveis por uma série de dificuldades para o trabalho de catequese.

Palavras-chave: Companhia de Jesus, sertão das Jacobinas, aldeamentos.

Abstract: In the second half of the seventeenth century, after the Portuguese Restoration, the settlement of the sertão of Portuguese America intensified. The process, defined in the documentation as "expansion for the inland routes", aimed at the

* Doutora em História pela UNISINOS. E-mail: anemecenas@gmail.com. 
constitution of villages and the formation of alliances, with the purpose of guaranteeing security in the commercial access to the routes of the cattle ranchers that followed from Bahia to Piauí, as well as As the constitution of a group of Indians that would restrain the formation of quilombos in the impenetrable routes of the sertão. Again, the religious orders were entrusted with the task of organizing the villages, disciplining the souls, and providing manpower at the entrances to the hinterland. The context of creation of the villages is presented based on the documentation of the Ultramarino Archive and that found in the collection Historical Records of the National Library of Rio de Janeiro. This work has as objective the multiple actors involved in the settlement of the sertão of Bahia, with emphasis on the Jesuits, who became the mediators between the worlds of the Indians and the interests of the curraleiros, responsible for a series of difficulties for the work of catechesis.

Keywords: Company of Jesus, sertão das Jacobinas, aldeamentos.

Recibido: 15 de noviembre de 2017.

Evaluado: 21 de diciembre de 2017. 


\section{Introdução}

Nos idos da segunda metade do século XVII, alguns missionários da Companhia de Jesus cruzaram o Atlântico em direção ao Novo Mundo e, enviados às aldeias do sertão da Bahia, junto ao curso do Rio São Francisco, depararam-se com uma série de conflitos locais decorrentes da expansão rumo ao interior da América portuguesa (Ferraz, 2015, p. 189). A área na qual eles se estabeleceram se constituía em importante rota comercial ocupada pelos "Tapuia", índios que eram tidos, ao mesmo tempo, como um "obstáculo" para os caminhos de dentro e como "solução" para os problemas de mão de obra, como apontou Capistrano de Abreu, ao analisar as tensões e os interesses dos caminhos do sertão:

O gado vacum dispensava a proximidade da praia, pois como as vítimas dos bandeirantes, a si próprio transportava das maiores distâncias, e ainda com mais comodidade; dava-se bem nas regiões impróprias ao cultivo da cana, quer pela ingratidão do solo, quer pela pobreza das matas sem as quais as fornalhas não podiam laborar; pedia pessoal diminuto, sem traquejamento especial, consideração de alta valia num país de população rala; quase abolia capitais, capital fixo e circulante a um tempo, multiplicando-se sem interstício, fornecia alimentação constante (...) De tudo pagava-se apenas em sal; forneciam suficiente sal os numerosos barreiros dos sertões (Abreu, 2000, p. 151).

Durante a fase de expansão do gado nos caminhos do São Francisco, dezenas de outros pequenos criadores e sesmeiros com grandes faixas territoriais, fixaram fazendas na região. Nem a doação das terras e nem a instalação das fazendas levaram em consideração o território indígena, o que tornou constantes os conflitos. E, no intuito de controlar os índios e contornar sua resistência, foram formadas forças-tarefa, capitaneadas por paulistas, convocados tanto para controlar os conflitos, quanto para destruir mocambos e aldeias indígenas. Em alguns casos, mocambos e aldeias acabaram se tornando refúgio de fugitivos, justificando a intervenção de tropas, como observaremos na análise da documentação. E foi para esta região de intensas disputas que as ordens religiosas foram enviadas no início da segunda metade do século XVII.

Como se pode constatar, os conflitos no sertão das Jacobinas já vinham ocorrendo antes mesmo da chegada dos religiosos da Companhia de Jesus. Em meio à campanha de expulsão dos holandeses, nos idos de 1651, as autoridades locais, juntamente com os sesmeiros, deflagraram combate aos índios que lá viviam. ${ }^{2}$

\section{Missões jesuíticas nas Jacobinas}

No ano de 1662, o visitador Jacinto de Magistris ${ }^{3}$ ressalta, em suas Instruções, a necessidade de os padres retomarem a catequese destes índios. Essa visita tinha como

\footnotetext{
${ }^{1}$ No Dicionário portuguez e brasiliano (1795, não há referência a "tapuya", a palavra mais próxima é tapuytáma, que corresponde a sertão, e tapy’a caaá porá, cujo significado é gentio. ${ }^{1}$ No Dicionário de R. Bluteau, não há referência a "tapuya", apenas a gentio, que aparece como pagão, gente baixa. ${ }^{1}$

${ }^{2}$ Carta para o Sargento maior Gaspar ... mas de Brum,Bahia 22 de maio de 1651 (Documentos Históricos. III, 1928, pp. 110-111). (grifos nossos).

${ }^{3}$ A presença do italiano culminou com a sua deposição do cargo de visitador do Brasil e do Maranhão. Os conflitos entre jesuítas e administradores no Maranhão e Grão-Pará foram constantes na segunda metade do século XVII. A administração das aldeias e descimento dos índios é um importante capítulo da inconstância das leis indígenas e das disputas por mão de obra. Em 1652, foi enviado para o Maranhão um novo capitão-mor com a ordem de libertar os índios escravizados. Em outro documento do mesmo
} 
objetivo apaziguar os ânimos e contornar os efeitos do envolvimento dos padres da Companhia nos conflitos políticos locais, situação bastante complexa em função das redes familiares, conforme iremos observar na guerra das missões das Jacobinas e dos interesses diversos entre os membros da Companhia de Jesus. E o modelo de redução, adotado desde o século XVII, pautado no "princípio da tutela política, jurídica e econômica dos índios" passou a ser empreendido nos sertões da América portuguesa (Leite, 2003, p. 289).

Em 1666, quatro anos após a visita de Jacinto de Magistris, o padre Jacob Roland e o então irmão João de Barros seguiram rumo ao sertão da Bahia. Iniciava-se, assim, um novo capítulo da ação dos jesuítas na América portuguesa, aquele em que atuariam junto às missões dos Tapuia.

A situação nos sertões era de instabilidade, devido aos constantes conflitos com os índios das Jacobinas. Visando contornar a situação, o então governador Antônio Guedes de Brito enviou o capitão Agostinho Pereira, a fim de assegurar o bom relacionamento com os índios:

Já a Vossa Mercê deve ter chegado o rumor da desconfiança com que todo o gentio de Jacobina está levantado, e quasi em termos de rompimento. E porque é este negocio de tanta importância, e a causa que tiveram também, que facilmente se tornarão aquietar, havendo pessoa que os componha, nos pareceu encarregar a Vossa Mercê por ser a de quem fazemos maior confiança, que tanto que a receber, mande buscar a Cahicaia e levando-o em sua companhia vá até aquellas aldeias, e de nossa parte segure a todos os Principaes, que este Governo está mui sentido de que houvesse, quem lhe ocasionasse esta alteração; e para castigar todos aquelles, que concorreram em dar-lhes a mínima causa delles estarem queixosos, e que para nós lhes significarmos melhor o nosso animo, e elles verem quão diferente é do que presumem mandamos vir de cada Aldeia os Principaes que Vossa Mercê trará consigo, a quem aqui queremos mandar dar os resgates do que mais se contentarem para elles e suas mulheres. ${ }^{4}$

Infelizmente, não foi possível localizar o relato que o capitão-mor Agostinho Pereira fez sobre a situação que encontrou nas aldeias, e, assim, avaliar se a troca de presentes, efetivamente, pacificou os ânimos. Sabe-se, no entanto, que foi em meio a estes conflitos e tentativas de negociação com os indígenas que os padres João de

ano, Antônio Vieira recebeu a Carta Régia que autorizava o descimento de índios ou o seu aldeamento. Nesse momento, o clima de instabilidade tomou conta dos colonos em Belém, que justificavam a escravidão indígena em virtude da mão de obra insuficiente para o trato nas lavouras e em serviços diversos. Diante desse cenário, houve o primeiro dos diversos conflitos, nos quais os jesuítas foram apontados como os responsáveis por desestabilizar a economia local em virtude da proibição da escravidão indígena. Com o anseio de solucionar o impasse, em 17 de outubro de 1653, foi instituída uma Provisão determinando o "cativeiro justo" e deixando que os casos fossem então examinados pelos oficiais de câmaras do Maranhão e Grão-Pará. Dois anos depois, em 9 de abril de 1655, Vieira consegue uma Provisão Régia que retira o poder antes concedido aos oficiais das câmaras e o concede aos padres da Companhia de Jesus. Essa portaria foi ratificada pelo Regimento de 14 de abril de 1655, que concedeu a administração das aldeias apenas aos jesuítas. Nesses locais, a população deveria ser de até cento e cinquenta casais e o trabalho indígena não poderia ser utilizado para lavouras de cana e tabaco. O conflito, contudo, não chegou ao fim, pelo contrário, ocorreu um novo levante em 1663, no qual a população do Maranhão e Grão-Pará se rebelou contra a jurisdição temporal e espiritual dos jesuítas. Esses problemas observados no Maranhão e Grão-Pará também foram sentidos na Capitania de São Vicente e, como no sertão das Jacobinas.

${ }^{4}$ Carta de Antônio Guedes de Brito ao capitão-mor Agostinho Pereira. Bahia 4 de janeiro de 1677 (Documentos Históricos. IX, 1929, pp. 34-35). 
Barros e Jacob Roland foram enviados para as aldeias da Jacobinas. Para Serafim Leite, eles chegaram ao destino no domingo da Santíssima Trindade, em 27 de maio de 1666 (Leite, 2003, p. 289). Contudo, essa foi a data da autorização do envio dos padres pelo Conde de Obidos, conforme aponta a portaria:

Porquanto o Padre Jacobo Rolant Religioso da Companhia de Jesus vae à missão da Jacuabina à conversão dos índios. O Provedor-mor da Fazenda Real deste Estado mande dar o dito Padre trinta mil reais para levar de resgates para o mesmo intento. Bahia Maio 27 de $1666 .{ }^{5}$

Convém ressaltar que, nesse período, conforme o Regimento de 23 de janeiro de 1667, o rei havia ordenado promover a propagação da fé, dividir a terra entre os índios e protegê-los. Além disso, o regimento estabelecia a necessidade de maior conhecimento acerca das línguas locais e, caso houvesse necessidade, imprimir vocábulos. ${ }^{6}$ Apesar disso, o que se depreende da documentação que analisamos, é que, devido ao poder que os fazendeiros da região desfrutavam, havia um flagrante desrespeito às orientações e a não aplicabilidade dessas leis.

O padre João de Barros logo se posicionou contrário à prática de arregimentação dos índios que habitavam o sertão. E, consequentemente, contestou a determinação real, que autorizava o descimento dos índios. Para Barros, o batismo dos indígenas deveria ocorrer na própria aldeia e sua retirada dos sertões era sua sentença de morte:

Digo que não há nenhuma razão de tirar os índios de seus sertões para iniciá-los nos princípios cristãos, mas que eles têm de ser batizados em suas próprias terras e nesses mesmos sertões. [...] Eles não suportam ser tirados à força nem iludidos, nem [mesmo se] levados pela fome e pela miséria. Com efeito, quantos de muitos milhares de índios sobreviveram sem a ajuda dos padres ou de outros quando levados à força de suas terras? Talvez um sobre mil esteja vivo. [... $]^{7}$

Como se pode constatar no trecho acima, o jesuíta reiterou a importância da presença religiosa na região, tanto para a administração espiritual, quanto temporal, uma vez que atuavam no provimento e na organização de todos os aspectos do cotidiano da aldeia.

E mesmo que os mais robustos entre eles possam resistir à inclemência do ar, matá-los-ia a fome, como nos ensina a experiência. Com efeito, quem poderia sustentar essa enorme multidão de homens? Nosso colégio, talvez? E onde? Nosso poderosíssimo rei, talvez? Mas nem com todo o tesouro da rainha. [...] Dirá alguém que, reduzindo-se os índios, se lhes ensinará a cultivar a terra, a plantar o que precisarem, a fazer roça para se sustentarem. Justo. Mas aí pergunto: por que não foi feito nos casos anteriores? E se foi feito, por que os

\footnotetext{
${ }^{5}$ Portaria que se passou o Padre Jacobo Rolant. Bahia, 27 de maio de 1666 (Documentos Históricos. VII, 1929, p. 248).

${ }^{6}$ Por meio da outorga de cartas régias, o rei permitia a formação de alianças com os índios, com o objetivo de evitar o confronto direto e de garantir o fornecimento de mão de obra, através dos descimentos indígenas, ou seja quando os índios eram retirados das aldeias e levados para as áreas de povoamento coloniais.

${ }^{7}$ Quaestio: Utrum tapuyae à Mediterranei proprius littora adducendi ut christianis inicientur sacris an non. À Jacobo Rolando ad Commiss. Missa, 1667. Roma: Arquivo Histórico da Companhia de Jesus, Bras., 3(2), f. 61 (Pompa, 2002, p. 92).
} 
índios são extintos? Finalmente, enquanto a terra não produz seus frutos para que eles possam se alimentar, como subsistiriam nesse meio tempo? Jejuando?. ${ }^{8}$

O missionário, além de sustentar a necessidade da presença dos padres nas aldeias, manifestou sua preocupação em relação à sobrevivência dos índios que viviam fora da missão e apontou para a necessidade de haver um incentivo para que plantassem nos aldeamentos. Já na carta de João de Barros, temos acesso à informação de que havia índios lavradores e caçadores nos aldeamentos (Leite, 2003, p. 283), e que a boa utilização da terra assegurava o êxito da missão. ${ }^{9}$ Barros tece, ainda, algumas comparações, trazendo dados sobre a experiência dos missionários nos aldeamentos do litoral.

Os padres desta nossa província, pelo menos muitos, no que diz respeito às coisas do sertão são cegos, pois nunca penetraram nele, a não ser por volta de trinta ou quarenta anos atrás, por acaso, nem sequer têm ideia do que aí se trata; erram quando pensam [...] me atacar com um argumento inatacável: dizem que, até o presente, sempre foi costume os padres reduzirem os índios conquistados das selvas e do sertão. [...] De modo algum penso em criticar ou negar os fatos dos nossos heroicos e santíssimos padres, já que os adoro e venero, por serem inspirados pelo Espirito Santo. Mas observo que naqueles tempos e circunstâncias esses fatos eram necessários; hoje os tempos e as circunstâncias são diferentes, para não dizer contrários. [...] Com efeito, os padres antigamente reduziam os índios para não viver junto a eles, contra qualquer costume, expostos a mil perigos ([...] imagino que os padres tirassem os índios do sertão por serem eles tão poucos no começo que seriam insuficientes para as missões do litoral e do sertão). ${ }^{10}$

Ao retomar a importância das missões realizadas no litoral no final do século XVI, o padre afirmou que estas se diferenciavam muito das que estavam sendo feitas no sertão, demonstrando, ainda, o quão distantes estavam estes missionários daqueles que viviam no colégio da Bahia. $\mathrm{O}$ desconhecimento sobre o sertão e sobre o que era viver nele foi a pauta de sua narrativa:

Certamente aqueles dos nossos que hoje cultivam este sertão e assistem os índios [...] se furtam aos ofícios da sociedade e à educação dos índios; ao ponto que este sertão, abandonado, é ocupado por europeus e angolanos, que todo o possuem e cultivam e vivem misturados nas aldeias dos índios. Eliminada portanto a causa do costume do descimento dos índios para o mar, deixa de existir o próprio costume. ${ }^{11}$

$\mathrm{Na}$ passagem acima ficam evidenciados os múltiplos discursos e as distintas posições assumidas por membros da Companhia de Jesus em relação à formação das aldeias no sertão. Para João de Barros, o grande investimento na conversão dos

\footnotetext{
${ }^{8}$ Quaestio: Utrum tapuyae à Mediterranei proprius littora adducendi ut christianis inicientur sacris an non. À Jacobo Rolando ad Commiss. Missa, 1667. Roma: Arquivo Histórico da Companhia de Jesus, Bras., 3(2), f. 61. (Pompa, 2002, p. 92).

${ }^{9}$ Este tema será uma constante nas cartas escritas pelo padre Antônio Andrade, missionário no aldeamento de Natuba, ao longo da primeira metade do século XVII.

${ }^{10}$ Quaestio: Utrum tapuyae à Mediterranei proprius littora adducendi ut christianis inicientur sacris an non. À Jacobo Rolando ad Commiss. Missa, 1667. Roma: Arquivo Histórico da Companhia de Jesus, Bras., 3(2), f. 61. (Pompa, 2002, p. 92).

${ }^{11}$ Ibíd.
} 
indígenas das regiões litorâneas prejudicava o pleno atendimento dos povos que viviam no sertão, defendendo que a ação catequética deveria adentrar o território americano.

Vejo que terei que travar um grande combate, mesmo que não queira estabelecer um conflito com quase todos nossos irmãos do Brasil, sobre o seu contrário ao hábito até aqui costumeiro das Missões do Brasil. (...) mas antes de responder às teses propostas por Vossa Reverendíssima, não seja importuno V. R. Ler com benignidade e examinar com cuidado estas notas premissas. (...)

Para mim está mais claro do que a luz do dia que as missões foram interrompidas e milhares de almas perdidas porque os padres não mantiveram a direção certa na instituição dos missões, querendo levar os índios para o litoral. (...)

Aqueles que tomam a parte afirmativa e pensam em me atacar com um argumento inatacável dizem que, até o presente, sempre foi costume os padre levarem os índios conquistados das selvas e do sertão, e é tão mais recomendável, de acordo com o exemplo profético, mas não com o praxe dos Heroicos Padres apostólicos (...) ${ }^{12}$

A retirada dos indígenas de seu território tradicional, segundo o missionário, prejudicava a continuidade da prática catequética. Propunha, em razão disso, que fosse feito um detalhado exame das ações anteriores para, assim, evitar a repetição de erros cometidos nos primórdios da atuação dos jesuítas

Para eles o clima marítimo sempre foi perigoso, porque eles não se acostumam; lembro a mesma coisa ter acontecido em minha província, nas cidades marítimas de Dunkerk e Berg, nas quais, se alguém é enviado para lá pelo provincial, a maioria adoece gravemente, pelo que os padres não acostumados àquele ar são enviados para lá só por motivos muito graves. E por que estes índios, mais fraco por natureza, não deveriam morrer perto do mar? E mesmo que os mais robustos entre eles possam resistir à inclemência do ar, os mataria a fome, como nos ensina a experiência. ${ }^{13}$

Ao defender a manutenção das missões no sertão das Jacobinas, sob a tutela da Companhia de Jesus, Barros relembrou o descimento dos índios liderados pelo padre Simão de Vasconcelos, na região de Niterói: ${ }^{14}$

No tempo em que era provincial, aquele ótimo zelador de almas que era Vasconcellos (que venero e tomo como exemplo pela doutrina e pelo zelo das almas) instituiu a famosa missão dos Geçaruru, recolhendo a grande multidão deles em Niterói e criou-os durante muitos dias com afeto paterno. E não morreram aos poucos, de fome e miséria, tanto que se pode dizer que não ficou ninguém? Só citou entre muitos exemplos para poupar tempo. (...) Aqui, os prudentes índios Sapoiá queriam saber, certos de nossa chegada, se os levaríamos conosco perto do mar. Diziam: se os padres tentarem, nos nunca o faremos, mas se eles ficarem aqui, adotaremos de bom grado os costumes

${ }^{12}$ Ibíd.

${ }^{13}$ Ibíd.

${ }^{14}$ Em 1648, Vasconcelos era reitor do Colégio do Rio de Janeiro. 
cristãos. Veja então V. R. como está certo o que eu disse no começo: que é impossível que as missões feitas desta maneira fiquem sem fruto $(\ldots)^{15^{3}}$

João de Barros esclarece que as experiências na costa deveriam ser, sim, consideradas para as estratégias de catequese dos indígenas do sertão, e que não pretendia criticar ou negar a ação dos padres que atuavam "inspirados pelo Espírito Santo". O descimento dos índios justificava-se pelo reduzido número de padres, do pouco conhecimento dos locais, da exposição aos "mil perigos". Mas lembra que estas eram as primeiras ações e o contexto era completamente distinto daquele que viviam no sertão na segunda metade do século XVII. Todos esses aspectos deveriam ser levados em consideração, ou, então, continuariam a repetir erros, comprometendo realização de novas experiências de missionação:

Mas seja-me permitido conservar um costume da sociedade. Não de uma província particular, mas da Sociedade inteira. Por quantas sejam [as províncias] não me lembro de ter ouvido alguma vez a Sociedade levar os índios a defender suas terras. $\mathrm{O}$ mesmo não costuma acontecer na Índia, no Japão, na China, no México, no Peru, no Chile, no Canadá, ou em outros lugares das Índias. Mas no Brasil as circunstâncias impõem que isso aconteça. Quais são? A índole dos índios: rude, inconstante, selvagem. Costumes alheios a qualquer prática humana. Sim, de fato. Mas estes são por acaso da mesma natureza de índole: rudes, inconstantes, selvagens? Leia alguém a história do México, do Peru, da Nova França, e outras; veja o quanto eles são alheios de qualquer costume humano. Sem dúvida, se prestarmos fé aos anais da Sociedade da Índia, de longe aqueles parecem piores do que estes. No entanto, a Sociedade os assiste em suas próprias terras, e nem cogita de mudar seu lugar. É preciso que esta provincial siga este costume, mesmo mil especificas razões impelindo para agir de outra forma. Por que razão, pergunto, aqui no Brasil deveria ser mais necessário do que no Peru, no Chile, no Canadá, etc? Já que dos dois lados há homens selvagens da mesma farinha? $(\ldots)^{16}$

Sua argumentação está alicerçada no conhecimento de outras experiências de conversão, que se assentaram sobre a grande capacidade de adaptação dos missionários à realidade local das vastas regiões do impérios ultramarinos em que atuaram. Experiências que consideraram este princípio de adaptação e negociação foram as mais exitosas:

Dizem que muito frequentemente acontece que depois de tirados os índios do sertão e levados para o litoral, imbuídos de preceitos cristãos, batizados, logo depois, arrependidos, eles fogem e voltam para suas terras. Não é possível não rir. Então, bons homens, de qual descimento vão falando, se logo que der vontade os índios podem voltar às suas terras? Que descimento é este (...) Nem deve aparecer extraordinário que os índios recaiam no vício de voltar de novo às suas terras, pois seria um grande milagre se não o fizessem. Com efeito, sendo arrancados desta maneira, e educados nos princípios da fé nova e batizados, são ternos na fé e não podem ser alimentados a não ser com leite, como diz o apóstolo dos Gentios, e não conseguem resistir ao desejo de sua querida pátria e

\footnotetext{
${ }^{15}$ Quaestio: Utrum tapuyae à Mediterranei proprius littora adducendi ut christianis inicientur sacris an non. À Jacobo Rolando ad Commiss. Missa, 1667. Roma: Arquivo Histórico da Companhia de Jesus, Bras., 3(2), f. 61. (Pompa, 2002, p. 92).

${ }^{16}$ Ibíd.
} 
digerir o dura comida (que não sei como se possa dar) que só homens santíssimos mal aguentariam (...). ${ }^{17}$

Para Serafim Leite, os jesuítas não foram indicados para as missões das Jacobinas, devido aos conflitos com os descendentes do Garcia D'Ávila, por conta da proximidade de suas terras com as aldeias e de sua relação com os índios locais, que eram tratados como escravos. João de Barros, por sua vez, destacou a atuação de outros religiosos, como os seculares e os capuchinhos franceses, na região:

Finalmente, se os sacerdotes não hesitam em penetrar este sertão, para trabalhar e assistir os Portugueses em Marasacara e, mais recentemente, no alto S. Francisco, distante muitas milhas, e não temem os índios, pois ganham sua comida e roupa, nós, nos mesmos lugares, hesitamos em conviver com os índios, ganhando-os para Deus? Talvez as almas dos índios estejam em condições piores do que antigamente? Ou nossas vidas são mais preciosas do que aquelas do padres Espanhóis e Franceses, ou mesmo dos seculares ${ }^{18}$

Tanto para o padre jesuíta Antônio Andrade, ${ }^{19}$ quanto para o padre Jacob Roland, a grande proximidade de fazendas de gado e os contatos que os colonizadores mantinham com africanos escravizados e índios eram os empecilhos para a conversão dos gentios. Roland propõe não apenas a interrupção do envio dos índios do sertão para o litoral, mas que, em virtude das querelas locais, alguns membros da Companhia contrários à missão no sertão, deveriam ser submetidos diretamente ao Geral, e não mais ao Provincial do Brasil, sugerindo que o Superior fosse Simão de Vasconcelos. Dentre os outros padres que apoiavam esta proposição estavam Antão Gonçalves, João Paiva e Manuel da Costa.

A despeito destas posições distintas, o trabalho missionário teve continuidade nas terras conhecidas como "Jacobina Velha", como se pode observar na Carta Ânua de 11 de setembro de 1667, que nos informa que após o regresso do padre Roland à Bahia, o padre João de Barros seguiu atuando na região. Nela, encontramos, também, informações sobre o número de batismos e sobre a catequese, sobre as línguas diferentes que estes índios falavam e sobre suas habilidades, já que alguns deles eram agricultores e caçadores, e outros, errantes:

(...) por que entendo, folgaria V. R. De me ouvir fallar das cousas deste Certão, o fato por estas regras com muita brevidade, pella súbita resolução de não dar lugar a ser extenso como quisera mas, o que nesta falta pode V. R. Saber do P. ${ }^{\text {e }}$ [Roland] porque nestas matérias o meu sentir he o seu, porque ambos vimos mesmo com os olhos, e quse apalpamos com as mãos, $\mathrm{m}^{\text {to }}{ }^{\text {deferente de que no }}$ Coll. ${ }^{\circ}$ se pratica.

O Emq. principal. ${ }^{\text {te }}$ ha de aver debates neste Coll. ${ }^{\circ}$ he saber fazer Aldeias neste Certão; já escrevi a V. R. EM outra ocasião, que podia e devia ser assim, porque deixando as outras razões, que naquela apontei, e uã delas deve faser muita força, que he a aver coração quando for necessário; o cazo presente o mostra, pois sem estudo (sic), deprendio esse Tapuya que atemorizava a todos desta

\footnotetext{
${ }^{17}$ Ibíd.

${ }^{18}$ Ibíd.

${ }^{19}$ As fazendas de gado que pertenciam ao Padre Antonio Pereira na região são atestadas no "Registro de uma petição ao Secretario Bernardo Vieria Ravasco”, no qual lemos: “ (...) na Serra da Jacobina, que começa donde o Padre Antônio Pereira tem introduzido algum gado". (Documentos Históricos, 1930, p $365)$.
}

30 Ane Mecenas. "Contra a prudência e a providência”: os Padres Jacob e João de Barros...21-39. 
Aldeia, que cordialmente nos amão, e desejão em tudo faser a vontade, deixando por amor de nos cousas que parecem, como são o beber vinhos azedos cõ q. Se embebedam, não cumdescender cõ alguã molher mã q. os incita (...) $E$ pedindonos que vamos lá formando queixas das nossas demoras não sei que rasão pode aver em contrario salvo a falta de sogeitos p. ${ }^{\mathrm{a}}$ esta missão (...) Se requer, digo, sejao verdadeiramente Apostolicos; eu, não porque tenho préstimo mas porque já estava nestas bandas, cõ o P.e Jacobo e algum mais, poderemos acudir a este gentio, emq.to não aver sojeitos q. se sacrifique a Deus (...). Entre tanto servirá o P. Jacobo de testemunho, q. se quiser falar tem não pouco que referir, de m.ta consolação aos zelosos, deq. se façao missões; eq. Belas se podem aqui fazer com menos trabalho ao mais inteiror deste Certão! P.e Comissario, em pouco anos não averá já Gentios. ${ }^{20}$

Para o jesuíta Barros, a constante presença dos curraleiros e paulistas na região gerava desconforto e desconfiança, o que justificava o envio de mais missionários a fim de proteger e converter os indígenas. Dentre os êxitos obtidos, ele ressalta que a presença da Ordem junto aos Tapuia havia diminuído o consumo dos vinhos locais entre os indígenas, principalmente, daqueles feitos com jenipapo. ${ }^{21}$ Vale lembrar que o padre Jacob Roland havia solicitado ao Padre Geral, que a missão das Jacobinas ficasse submetida diretamente ao Provincial do Geral e não ao Provincial do Brasil. Recomendou, ainda, que o superior deveria ser o padre Simão de Vasconcelos, porque ele era um dos poucos que defendia a missão no sertão assim como os padres Antão Gonçalves, João de Paiva e Manuel da Costa. A posição assumida por Roland pode ser observada na carta escrita por Simão de Vasconcelos, na qual defende sua permanência nas missões das Jacobinas. Nela, Vasconcelos apresenta um panorama do trabalho realizado nas missões, destaca as críticas feitas ao trabalho do padre Roland no sertão, para, ao final, contestá-las:

De acordo com vossa e também a minha ideia, que sempre foi aquela de enviar missões frequentes entre os povos desta província, foi enviado no longínquo sertão o padre Jacob Roland, belga, ardente de zelo apostólico, junto com João de Barros. No caminho houve milagrosos acontecimentos com Lusitanos, Angolanos, índios (...); assim que esta missão, pelo menos no que for necessário, é bastante gloriosa, e deve continuar no futuro. Só uma coisa, entre todas, desagradou a este colégio, o que necessita que V. P. Mande mais rapidamente possível parecer a respeito. Com efeito, o Padre Roland, no fim desta missão fixou sua residência numa das aldeias dos Tapuia, no sertão, longe desta cidade 130 léguas, que são três mil passos, onde purificou já muitos com batismo, querendo purificar os restantes, tendo em mente de permanecer para sempre entre os índios, por razões que escreveu a V.P. Este fato foi mal aceito, pensando alguns que isto aconteceu por fraude do demônio, porque aquelas almas, sendo batizadas tão facilmente em lugar impróprio, uma vez abandonadas pelos missionários, cairiam em pecados ainda mais graves. ${ }^{22}$

\footnotetext{
${ }^{20}$ Carta do P. João de Barros ao Pe. Comissário Antão Gonçalves. Bahia, 11 de setembro de 1677. ARSI, Bras. 3 (2), f. 51 (Pompa, 2003, p. 320) (grifos nossos).

${ }^{21}$ João Azevedo Fernandes, em sua obra Selvagens Bebedeiras, apresentou um perfil das redes de sociabilidades constituídas em torno da bebida e o papel do álcool na dinâmica local dos índios.

${ }^{22}$ Carta do P. Simão de Vasconcelos ao P. João Paulo Oliva, Preposto Geral da Cia., Roma, Bahia, 7 de novembro de 1667, ARSI, Bras. 3 (2) f. 57.
} 
Para Serafim Leite, ao longo do século XVII, "insensivelmente começaram a coexistir duas categorias de Jesuítas no Brasil, os do Colégio e os das Aldeias". (Leite, 2003, VII, p. 100). Ao relatar as divergentes opiniões existentes sobre a continuidade do trabalho missionário nos "caminhos de dentro", Simão de Vasconelos aponta para a existência destas duas categorias, que divergiam quanto à adaptação dos preceitos doutrinários nas missões.

$\mathrm{O}$ argumento deles é que este gesto foi contra a prudência e contra a obediência. Contra a prudência porque foi contra a norma estabelecida há tempo imemorável nesta província porque feito contra a norma estabelecida há tempo imemorável, nesta província, e aprovada pelos Provinciais, Visitadores e Gerais, contra o parecer de todos neste caso contingente e, o que é mais grave, contra as instruções do Pe. Comissário, pedidas pelo próprio Padre Roland por escrito e, finalmente, contra as graves razões ali contidas. Por tudo isso eles acham que foi contra a prudência. Contra a obediência porque o P. Comissário mostrou que nunca dera esta licença, mas mandou para que estas gentes fossem reduzidas para perto das nações pacificadas, como sempre foi de costume, para lugares mais próximos dos Lusitanos, para que, recebida a fé, fossem obrigados, com a pressão da Igreja, a cumprir a promessa de se abster das muitas mulheres, do veneno da carne humana e das superstições. ${ }^{23}$

Os Superiores justificavam a desaprovação do modus procedendi adotado pelos padres Jacob Roland e João de Barros por que descumpria os critérios da prudência e da obediência. Para Eisenberg, o modo de proceder jesuítico consistia numa "dialética entre obediência e prudência resultante dos elementos voluntarísticos da doutrina espiritual de Inácio de Loyola" (Eisenberg, 2000, p. 19). A obediência era um dos três votos básicos e, para os Jesuítas, um voto especial, na medida em que professavam obediência direta ao Papa, conforme o movimento tomista, da seconda scholastica. A desobediência estava no descumprimento do modelo de catequese, uma vez que ambos propunham a fixação dos missionários na região em que os índios viviam e não em outra área destinada para a missão. Vasconcelos problematiza o modelo seguido desde o século XVI, refletindo sobre os resultados alcançados:

Apesar disto, pelas pessoas que vi e com que tratei, suspeito que isso não foi sem o auxílio divino, talvez ele permitiu isso para confundir a prudência humana e mostrar outros caminhos, onde tantos milhares de almas podem ser salvas. Por isso, penso que seja necessário submeter à prova esta suposta conversão e batismo de um tão grande número de almas para que se este evento é casual ou provém de Deus. Com efeito, parece um gesto duro e imprudente destruir hoje o que foi construído com tanto esforço missionário ontem, e dissolver a fé que eles ofereceram áquelas gentes. ${ }^{24}$

Como se sabe, a orientação que os padres das aldeias das Jacobinas haviam recebido era de que deveriam apenas converter os índios, "pacificá-los" e, então, retirálos de suas terras para viver em outra aldeia próxima da administração local, recomendação também feita ao ajudante Luis Alvares. ${ }^{25}$ Sete anos depois, o capitão-

\footnotetext{
${ }^{23}$ Carta do P. Simão de Vasconcelos ao P. João Paulo Oliva, Preposto Geral da Cia. Roma, Bahia, 7 de novembro de 1667, ARSI, Bras. 3 (2) f. 57. (grifos nossos)

24 Ibíd.

${ }^{25}$ Regimento, que se passou ao Ajudante Luis Alvares para ir passar as Aldeias da Jacobina para a Serra do Orobó. Bahia, 2 de maio de 1651. (Documentos Históricos, V, 1928, pp. 57-59).
} 
mor Domingos Barbosa Calheiros ${ }^{26}$ recebeu semelhante incumbência, devendo encarregar-se do traslado dos índios das Jacobinas para a Serra do Oboró. Parece-nos, portanto, que se somam às reprimendas sofridas pelos dois missionários, em decorrência do desrespeito às orientações da Companhia de Jesus, apontadas pelo Superior jesuíta, a lógica de interesses das elites locais, que almejavam a retirada dos índios daquela localidade, visando à expansão de suas atividades de criação de gado e exploração de salitre. $^{27}$

Dois anos depois, em 1669, contendas envolvendo a família de Garcia de Ávila promoveram a destruição de três aldeias Kiriri, que haviam sido instaladas pelo padre Jacob Roland e pelo irmão João de Barros. Apenas a aldeia de Santa Tereza de Canabrava não sucumbiu. ${ }^{28}$

De acordo com as Ânuas, em 1669, após três anos de experiência junto às aldeias do sertão, três missões foram destruídas pelo curraleiros de Garcia d'Ávila: a aldeia dos Boimés, no Itapicuru; a aldeia dos Caimbés, em Maçacará; e a aldeia de Mongurus, em Jurumuabo (Geremoabo). Já as outras aldeias Kiriri permaneceram sob a tutela dos jesuítas até 1758 , quando se deu a elevação das aldeias à categoria de vila, um ano antes da expulsão.

Na carta de 15 de outubro de $1669,{ }^{29}$ o padre Antônio da Fonseca informa que, de acordo com o padre Jacob Roland, a destruição das aldeias havia sido promovida pela gente da Torre, após terem sido informados de que os padres da Companhia solicitariam ao rei de Portugal a doação de três léguas de terras aos indígenas. A situação ganhou grandes proporções porque os jesuítas que atuavam nas aldeias se mobilizaram para apresentar uma denúncia junto ao tribunal através do Conservador Eclesiástico. Contudo, a denúncia acabou não acontecendo e o padre Antônio Pereira, que era tio do curraleiro Gárcia de Ávila, pediu misericórdia ao então reitor do colégio da Bahia, padre Antônio Forti, com o intuito de contornar os problemas locais sem alardeá-los ao rei de Portugal. Isto, no entanto, não impediu a destruição promovida por meio de uma expedição, que contou com tropas de índios e capitães mores convocados para destruir um mocambo, e não um aldeamento, como efetivamente ocorreu.

Dessa forma, no dia 21 de maio de 1699, foram publicadas algumas orientações para o Capitão Fernão Carrilho, relativas às providências que deveriam ser tomadas para a entrada nos mocambos de Geremoabo. ${ }^{30}$ Segundo as instruções, o capitão Fernão Carrilho devia partir junto com o capitão do Campo, Gaspar Cunha, da Bahia, para a

\footnotetext{
${ }^{26}$ Regimento que levou o Capitão-mor Domingos Barbosa Calheiros na jornada do Sertão. Bahia, 5 de setembro de 1658 (Documentos Históricos. V, 1928, pp. 321-327).

${ }^{27}$ Esse foi um processo de ação em diferentes frentes, com alianças em virtude de uma luta contra um inimigo comum, o que aparentemente, conforme a documentação, levou a um desgaste na relação entre os índios das Jacobinas e os paulistas. Partiram para outra articulação, com o envio dos padres, que além de uma indicação do Superior foi estabelecida uma portaria de autorização do Governador Geral. A última medida parecia ter solucionado o problema, contudo, os padres reiteravam a permanência na localidade e contestavam o descimento indígena.

${ }^{28}$ Quaestio: Utrum tapuyae à Mediterranei proprius littora adducendi ut christianis inicientur sacris an non. À Jacobo Rolando ad Commiss. Missa, 1667. Roma: Arquivo Histórico da Companhia de Jesus, Bras., 3(2), f. 61 (Pompa, 2002, p. 92).

${ }^{29}$ Ibíd.

${ }^{30}$ Regimento que levou Fernão Carrilho que foi por Capitão para fazer entrada aos mocambos de Geremoabo (Documentos Históricos. IV, 1928, pp. 192- 194).
} 
Torre de Garcia d'Ávila. ${ }^{31}$ Lá receberiam espingardas, pólvora, balas e contariam com o apoio de dez homens, além de "dois alqueires de farinha, quatro barris para metter pólvora e munições". ${ }^{32}$ A recomendação era de que o grupo passasse também na residência do padre Antônio Pereira, a fim de agregar um grupo de mestiços à tropa:

Ordenará ao Capitão Gaspar da Cunha, que ajunte toda a gente da sua tropa, e ao Capitão dos Indios, todos os que forem capazes de tomar arma. E pedirá aos Capitães o mantimento, que lhe parecer bastante, para a jornada que ha de fazer outros; dos quaes ha de dar recibo, para se pagarem por conta da presa, que se ha de tomar; e se deterá somente ali, emquanto reconduz a dita gente, e não chegam os Capitães pretos que ficam ajuntando a sua gente para se irem incorporar com ele. ${ }^{33}$

A entrada deveria ser realizada o mais breve possível. Sabe-se que os quarenta índios que participaram dessa entrada que visava à destruição dos aldeamentos Kiriri, em Geremoabo, foram índios do Geru, aos quais foi prometido que receberiam doze cavadores, doze foices ou machados, ${ }^{34}$ vinte côvados de baeta vermelha, duas dúzias de espelhos pequenos, dois maços de velas, quatro milheiros de anzóis e fitas de seda para as mulheres. ${ }^{35}$ Dezenove deles foram à Bahia e lá receberam também "ceroulas de panno de linho, uma faca, um pente." ${ }^{36}$ Mas eles não foram os únicos a participar.

Se o dito Fernão Carrilho parecer segundo as notícias que tem, e achar daqueles mocambos, que a sobredita gente que leva, não é bastante procurará digo poder, procurará agregar a si toda a gente que poder de brancos, pretos, mulatos, e todo o gênero de gente, que tiver capaz de jornada não sendo soldados pagos, nem captivos.

Como se pode constatar, cabia aos sesmeiros fazer uma ampla convocação, devendo, no entanto, "guardar grande silencio e cautela" para que a notícia não corresse e, assim, pudessem contar com a estratégia da surpresa para empreender tal ação, que deveria ser rápida.

(....) procurará dispor o assalto que lhe há de dar de maneira, que todos os que pretenderem fugir prisioneiros, não lhe advertindo mais cousa alguma sobre este particular: porque o tempo, a ocasião, o logar, e a sua muita experiência ensinarão o que deve melhor obrar para se conseguir o intento com felicidade, que espero.

\footnotetext{
${ }^{31}$ Atualmente, o castelo dos D’Ávila, como é conhecido, pertence ao município de Mata de São João e fica localizado na Praia do Forte. As ruínas da edificação foram tombadas pelo IPHAN.

${ }^{32}$ Portaria que se passou para se dar farinha e barris para a pólvora à gente que vae à entrada do mocambo (Documentos Históricos. IV, 1928, p. 408).

${ }^{33}$ Regimento que levou Fernão Carrilho que foi por Capitão para fazer entrada aos mocambos de Geremoabo (Documentos Históricos. IV, 1928, p. 192).

${ }^{34}$ Não recebem armas visto que era proibido. Caso alguém fornecesse armas poderia ser morto ou poder os bens conforme o Regimento de Roque da Costa Barreto de 23 de janeiro de 1677. In.: Regimento que trouxe Roque da Costa Barreto, Mestre de campo general do Estado do Brasil. 23 de janeiro de 1677 (Documentos Históricos. VI, 1928, p. 317).

${ }^{35}$ Portaria para o Provedor-mor mandar dar o necessário para a entrada do Mocambo a que vae o Capitão Fernão Carrilho para se despender com os Indios que o acompanharem (Documentos Históricos. VII, 1929, p. 407).

${ }^{36}$ Portaria para o Provedor-mor mandar dar fardas aos índios que vieram com o Capitão Fernão Carrilho. (Documentos Históricos. VIII, 1929, p. 90).
} 
Mortos e prisioneiros todos que houver no dito mocambo na forma que digo, no antecedente capitulo; e tomados os mantimentos necessários, para voltar com toda a gente, mandará queimar, e assolar o mocambo, e destruir todas as plantas dele; e marchará com toda a gente em direitura a esta praça, para da cadeia della se restituírem as peças a seus donos, pagos os custos da jornada, na forma que é estylo. Tendo particular cuidado se não desencaminhe peça ou cria alguma, penas de a pagar na cadeia, qualquer que a descaminhar.

Nos documentos consultados, não é apresentado o número de índios tapuias que viviam no mocambo de Geremoabo. Entretanto, é possível que tenha sido um grande número, visto que dois outros capitães receberam portaria, comunicando o deslocamento para atender a essa demanda. Agostinho da Silva Bezerra e Matheus Fernandes deveriam seguir para Itapecurú, para se juntar à outra tropa e levar pólvora e balas. A orientação era a de que deveriam partir e trocar de cavalo a cada cinco léguas, e, por estar a Serviço de Sua Alteza, qualquer pessoa que encontrassem no caminho deveria entregar um cavalo e, também, um negro para que pudessem chegar ao destino com maior brevidade. ${ }^{38}$

Apesar de todas as evidências apontarem para uma mal intencionada ação de Garcia d'Ávila e do Padre Antônio Pereira, o então reitor do colégio jesuíta da Bahia, padre Antônio Farti, concedeu misericórdia, uma vez que as missões da Bahia se encontravam sob a tutela do reitor deste colégio. Padre Farti publicou um documento de treze parágrafos, fundamentados no direito civil e canônico, no qual expunha os motivos que o fizeram encerrar o conflito e não iniciar um processo judicial contra os responsáveis que promoveram a destruição das três aldeias.

De acordo com Capistrano de Abreu, esses conflitos no sertão ocorreram em decorrência da disputas pela posse da terra, porque os índios não quiseram ceder "pacificamente" o espaço aos sesmeiros, ou por terem se "apropriado" indevidamente do gado dos curraleiros (Abreu, 2000, p. 168). A solução, segundo o consagrado historiador, era a saída das terras indígenas próprias para a criação do gado, visto que “ abundavam terras devolutas para onde os índios podiam emigrar" (Abreu, 2000, p. 168). Esta, contudo, uma vez que a ocupação levada a efeito pela elite do sertão não levou em consideração os territórios tradicionais das aldeias indígenas, como estabelecia a própria legislação metropolitana, e nem quando os espaços contavam com a presença dos religiosos. A justificativa apontada por Capistrano legitima a ação do colonizador e culpabiliza o índio pelas querelas, quando, na verdade, e como procuramos demonstrar através da análise da documentação, a própria legislação se mostrou ambígua, ao favorecer -ao menos, em nível de discurso-, ora os índios, ora os fazendeiros e curraleiros. No Quadro 1, é possível observar as aldeias atendidas pelos jesuítas no sertão da América portuguesa e que foram destruídas:

\footnotetext{
${ }^{37}$ Regimento que levou Fernão Carrilho que foi por Capitão para fazer entrada aos mocambos de Geremoabo (Documentos Históricos. IV, 1928, p. 193).

${ }^{38}$ Portaria que levaram os Capitães Agostinho da Silva Bezerra e Matheus Fernandes que vão à entrada dos Mocambos (Documentos Históricos. IV, 1928, p. 409).
} 


\begin{tabular}{|c|c|c|c|}
\hline Período & Aldeia & Grupo indígena & Freguesia \\
\hline $1639-1669$ & $\begin{array}{l}\text { Massacará da Santissima } \\
\text { Trindade }\end{array}$ & Kaimbé & Jeremoabo \\
\hline $1666-1669$ & $\begin{array}{l}\text { Nossa Senhora de Nazaré } \\
\text { Itapicuru }\end{array}$ & Moritise, Boimé & $\begin{array}{l}\text { Nossa Senhora de Nazaré de } \\
\text { Itapicuru }\end{array}$ \\
\hline $1666-1669$ & Jeremoabo & Moritise, Monguru & São Antonio da Jacobina Velha \\
\hline $1666-1758$ & Nossa Senhora de Natuba & Kiriri & Santo Amaro \\
\hline $1666-1669$ & São Francisco Xavier & $\begin{array}{l}\text { Sapiá, Payayá, Borcá,, } \\
\text { Separenhenupã, Cuparans }\end{array}$ & São Antonio da Jacobina Velha \\
\hline $1666-1669$ & Santa Cruz & Acará, Procá, Rodelas & São Antonio da Jacobina Velha \\
\hline $1666-1669$ & Santo Inácio & Secaquerinhe, Cacherinhen & São Antonio da Jacobina Velha \\
\hline $1667-1758$ & Canabrava & Kiriri & $\begin{array}{l}\text { Nossa Senhora de Nazaré de } \\
\text { Itapicuru }\end{array}$ \\
\hline
\end{tabular}

Quadro 1- Aldeias jesuíticas no sertão do Rio São Francisco em 1667

É possível observar que das seis aldeias, administradas pelos jesuítas no sertão da Bahia em 1669, cinco foram instituídas após a portaria que autorizou os padres Jacob Roland e João Barros a adentrarem nos sertões. Por meio da localização das freguesias é possível identificar a abrangência da zona de atuação desses membros da Companhia de Jesus num período de três anos incompletos. Todas elas estavam localizadas nas proximidades, ou nas áreas de terras doadas aos sesmeiros na região, o que levou aos confrontos com Francisco Dias D’Ávila, Antônio Guedes de Brito e do padre Antônio Andrade. Nesse quadro não se encontra elencada a aldeia de Santa Tereza de Canabrava, porque, de todas, foi a única que não foi destruída.

\section{Outros caminhos para além das Jacobinas}

Em relação aos povos que habitavam as aldeias, constata-se a diversidade de grupos que habitavam a mesma região (apenas em Massacará havia um único grupo), como também, o grande número de comunidades indígenas sob a tutela da Companhia de Jesus. Convém ressaltar que muitos dentre os índios que sobreviveram aos ataques dos sesmeiros, fugiram e adentraram ainda mais no sertão, e que houve um significativo número deles que seguiu com os padres para Canabrava e Natuba, compondo as aldeias Kiriri que seriam formadas posteriormente. Essa pode ser a explicação para as semelhanças que encontramos por meio da documentação consultada entre as festividades, hábitos alimentares e rituais de sepultamentos dos Kiriri, descritas pelos 
padres jesuítas, e as práticas dos Moritises, Boimés e Payaya, que foram forçados a conviver nas aldeias.

Após a destruição das aldeias em 1669, duas aldeias passaram a ser administradas por franciscanos: Massacará da Santissima Trindade e Nossa Senhora de Nazaré de Itapicuru. Em outras aldeias a destruição foi total, como foi o caso de Jeremoabo, São Francisco Xavier, Santo Inácio, Santa Cruz, todas localizadas na freguesia de Santo Antônio da Jacobina Velha. É possível que parte dessa população tenha sido incorporada à aldeia que os jesuítas criaram na mesma freguesia, em 1685, e que se chamou Acará. Sobre ela, Serafim Leite informa que era composta por índios Acará, Procá e Rodela, e que os padres ficaram na região por pouco tempo, apenas até 1696.

Passado o evento de 1669, os padres da Companhia se dedicaram a outras duas frentes de atuação: no "sertão do Rio São Francisco" e no "sertão de Rodelas". Em Rodelas, os padres administraram a aldeia de Carurus, onde viviam índios Procá e Rodela, até 1687, enquanto que no "sertão do Rio São Francisco", os padres atuaram em três aldeias: São Gonçalo do Salitre (1669-1696), Sorobabé (1669-1696), Curumambá (1671-1696).

Essas aldeias, formadas após a destruição de 1669, foram também destruídas pelos D’Ávila em 1696. Isso indica a continuidade dos conflitos entre índios e sesmeiros, e assinala para a descontinuidade do trabalho jesuítico ameaçado pelos interesses de particulares da região. Para Jonh Herming e para John Russell-Wood, as dificuldades encontradas no processo de conversão foram também gerados pela "inflexibilidade do jesuíta" diante das práticas dos índios. Para ambos os autores, os capuchinhos franceses teriam sido mais tolerantes nessa questão (Russel-Wood, 2014, p. 286). Entretanto, conforme foi possível analisar na documentação, a interrupção do trabalho missionário não pode ser creditada exclusivamente à menor ou maior tolerância aos costumes dos Kiriri, uma vez que em muitas missões os jesuítas se mantiveram atuando por décadas ininterruptas. Entendemos que as aldeias jesuíticas, assim como também as de outras ordens religiosas, devem ser inseridas na lógica das disputas por espaço, das constantes convocações para participação das tropas, como também no estabelecimento de alianças entre as elites locais, que, muitas vezes, inviabilizaram a missionação.

No que se refere, ao conflito de 1669 , a própria Companhia tinha opiniões divergentes em relação à ação dos padres nos sertões das Jacobinas, não havendo consenso quanto ao projeto de missionação a ser adotado junto aos Tapuia. E, como procuramos demonstrar, apesar das tentativas, os padres João de Barros e Jacob Roland não conseguiram o apoio de seus Superiores. Outro ponto que deve ser levado em consideração quando analisamos essa primeira experiência nos sertões das Jacobinas, é que duas aldeias não sucumbiram às expedições e os jesuítas as administraram até 1758 . Além disso, entendemos que faz-se necessário analisar a ação desses padres para além da dicotomia tolerância ou inflexibilidade, visto que essa construção interpretativa nos impede de observar e avaliar o protagonismo indígena nesse processo, que implicou a aceitação da vida em aldeia e a adoção de certos padrões de conduta moral e religiosa.

Também os embates entre Francisco Dias D’Ávila e os capuchinhos nos revelam a lógica da ocupação territorial dos fazendeiros e curraleiros e as consequências das expedições que visavam à destruição das aldeias, reforçando a importância destes conflitos para a descontinuidade do trabalho missionário. Os relatos do frei capuchinho 
francês Martinho de Nantes, que chegou a Recife nos idos de 1671, nos trazem com riqueza de detalhes os conflitos na região dos Tapuia. Para o frei, o sesmeiro era a personificação dos perigos que todos enfrentavam e dos males que caracterizavam o cotidiano nos sertões, que incluíam o apresamento ilegal de índios, a matança dos nativos e a apropriação das terras das aldeias.

Após essa tentativa de organização das aldeias nos sertões, os padres voltaram suas atenções para Canabrava e, mais tarde, fundaram outras três na rota dos caminhos do São Francisco:

A primeira entrada que busca ao Ryo de S. Francisco pela costa do mar, se acha hoje muy copiosamente povoada thé distância de 60 legoas, aonde fica a cidade de Sergipe Del Rey; porque a vizinhosa do mar fez desde o principio esse caminho mais seguido e para aquella parte foi pendendo o maior concurso. E esta he a razam porque também se acha mais assistida de sacerdotes, em freguesias, em cazas de missão e em capelas. E com serem muitos, ainda assim mostra a cada passo a experiência em muitas pessoas, a quem para a hora da morte falto confessar, que não são tantos os Ministros eclesiásticos, quantos tanta multidão de gente havia mister. Mas todavia assim ou assim por esta banda se experimente muito menos falta.

Pello segundo caminho do meyo, sahe a falta mais sensível porque na distância da ditos 100 legoas the o Ryo de S. Francisco, não havião mais que três freguesias, a saber em Itapicurú, com Lagarto, e em Itabayana, (de dous anos a esta parte se lhe acrescentou mais huma a Geremoabo), com tudo, além de 4 cappelas particulares, ha por essa parte sinco cazas de missão de religiosos da Sagrada Companhia de Jesus em aldêas de índios, a saber em N. S. do Socorro, em Canabrava, em Sacos do Morcegos, em Natuba, em Manguinho. (AHU/BA, Castro e Almeida, cx. 3, doc. 342.)

A experiência dos três anos junto às aldeias Kiriri do sertão da Bahia foi de suma importância para a continuidade da atuação jesuítica na região e, principalmente, para que os problemas que haviam enfrentado não voltassem a se repetir. Foi durante essa primeira tentativa que os jesuítas começaram a adquirir um conhecimento das línguas faladas na região que os auxiliou na continuidade do trabalho em Canabrava e na criação, em seguida, de Natuba, Saco dos Morcegos e Geru.

\section{Referências}

Abreu, C. (2000). Capítulos de História Colonial (1500-1800). 7a edição, São Paulo; Belo Horizonte: Publifolha; Itatiaia.

Documentos Históricos. (1928). Vol. III. Documentos da Biblioteca Nacional 16481661. Rio de Janeiro: Biblioteca Nacional.

Documentos Históricos. (1928). Vol. IV. Documentos da Biblioteca Nacional 16481672. Rio de Janeiro: Biblioteca Nacional.

Documentos Históricos. (1928). Vol. V. Documentos da Biblioteca Nacional 16501668. Rio de Janeiro: Biblioteca Nacional.

Documentos Históricos. (1929). Vol VII. Documentos da Biblioteca Nacional 16601670. Rio de Janeiro: Biblioteca Nacional. 
Documentos Históricos. (1930). Vol. XVIII. Documentos da Biblioteca Nacional 16391655. Rio de Janeiro: Biblioteca Nacional.

Eisenberg, J. (2000). As missões jesuítas e o pensamento político moderno: encontros culturais, aventuras teóricas. Belo Horizonte: Editora da UFMG.

Ferraz, M. del S. (2015). A sociedade colonial em Pernambuco. A conquista dos sertões de dentro e de fora. In: Frafoso, J. \& Gouvêa, M. de F. Brasil Colonial. 15801720. Vol. 2. Rio de Janeiro: Civilização Brasileira.

Leite, S. (2003). História da Companhia de Jesus. Tomo V. São Paulo: Edições Loyola.

Hartog, F. (2004). Memória de Ulisses: narrativas sobre a fronteira na Grécia antiga. Trad. Jacyntho Lins Brandão. Belo Horizonte: Editora UFMG.

Hemming, J. (2007). Ouro Vermelho. A conquista dos Índios Brasileiros. Trad. Carlos Eugênio Marcondes de Moura. São Paulo: EDUSP.

Pompa, C. (2002). O lugar da utopia: os jesuítas e a catequese indígena. Novos Estudos. N. 64. Campinas.

(2003). Religião como tradução: missionários, Tupi e "Tapuia" no Brasil colonial. Bauru: EDUSC.

Russel-Wood, J. (2014). Histórias do Atlântico português. São Paulo: Editora da Unesp.

Ricupero, R. (2009) Poder e patrimônio: o controle da administração colonial sobre as terras e a mão de obra indígena. In: Souza, L. de M.; Furtado, J. F.; Bicalho, M. F. (Orgs.). O governo dos povos. São Paulo: Alameda, p. 355-370.

Santos, F. L. (2012). Da catequese à civilização: colonização e povos indígenas na Bahia (1750-1800). Salvador/BA: Universidade Federal da Bahia/Faculdade de Filosofia e Ciências Humanas.

Zeron, C. (2014). Da farsa à tragédia: A guerra de facções que pôs fim às esperanças de Antônio Vieira por um Quinto Império e transformou o modo de atuação dos jesuítas do Brasil. In: Galdeano, C.; Artoni, L. M.; Azevedo, S. M. (org.). Bicentenário da Restauração da Companhia de Jesus (1814-2014). São Paulo: Loyola, pp. 167-198. 